\title{
Dose-response curves for the effect of gastrin II on acid gastric secretion in man
}

\author{
G. M. MAKHLOUF, J. P. A. McMANUS, AND W. I. CARD \\ From the Gastro-intestinal Unit, Western General Hospital, Edinburgh, and \\ the Department of Medicine, University of Edinburgh
}

EDITORIAL SYNOPSIS The acid gastric secretory response pattern of a single human subject to gastrin II by injection has been subjected to detailed statistical analysis. Both linear and sigmoid relationships between log dose and response were obtained, depending upon the parameters selected. There is a preliminary indication that the maximal acid response to gastrin II is similar to the maximal acid response to histamine.

The recent preparation of pure gastrin by Gregory and Tracy (1964) has rendered possible the investigation of its properties in man. Our aim was to study the secretory behaviour of the human stomach in response to continuous infusion and to graded single intravenous injections of gastrin II. Our data were obtained in both cases from the same healthy adult male volunteer (weight $84 \mathrm{~kg}$.). The gastrin II used in these experiments was given by Professor R. A. Gregory.

\section{METHODS}

The subject was fasted overnight. In the morning, a no. 7 Levin tube was passed via the nose into the stomach and sited radioscopically so that its tip lay in the most dependent part of the stomach. The tests were carried out in a quiet, warm room, with the subject lying on his left side. Continuous attention was given to ensure constant patency of the tube and a consequent steady flow of secretion. Saliva was collected by five dental pledgets of cotton wool placed in the fornices of the cheeks and below the tongue and changed at frequent intervals. Secretion was collected for an hour before the test and labelled 'basal' secretion. Collections were subsequently made at intervals of five minutes and pooled into samples corresponding to 20 minutes' flow for titration. Acidity was determined by titration against $0 \cdot 1$ normal $\mathrm{NaOH}$, using phenolphthalein as indicator.

MATERIALS AND INFUSION Gastrin II, dissolved in citrate buffer and its concentration adjusted exactly to $10 \mu \mathrm{g} . / \mathrm{ml}$., was placed in $1 \mathrm{ml}$. ampoules. On the morning of each experiment, the contents of one or more ampoules were washed out with sterile water into a standard $50 \mathrm{ml}$. syringe. Differential weighing of the ampoules used permitted an accurate estimate of the dose extracted from them. The dose was varied by the number of ampoules used and by any subsequent dilution of the syringe contents. A constant speed of delivery of $11 \cdot 19 \mathrm{ml} . / \mathrm{hr}$. was used in all experiments. Continuous infusion lasted for a period of three hours and the doses used ranged from 0.2 to $67 \mu \mathrm{g}$. $/ \mathrm{hr}$. of gastrin II.

SINGLE INTRAVENOUS INJECTIONS The dose of gastrin was dissolved in $10 \mathrm{ml}$. of sterile water. Doses above $5 \mu \mathrm{g}$. were injected slowly over a period of three to five minutes. Doses below this were injected more rapidly. The range of single intravenous doses was $0.5 \mu \mathrm{g}$. to $50 \mu \mathrm{g}$. of gastrin II.

The order of doses was randomized and the intervals between experiments were varied, both for continuous infusion and single intravenous injections.

\section{RESULTS}

CONTINUOUS INFUSION The secretory responses to a series of infusions with increasing doses of gastrin

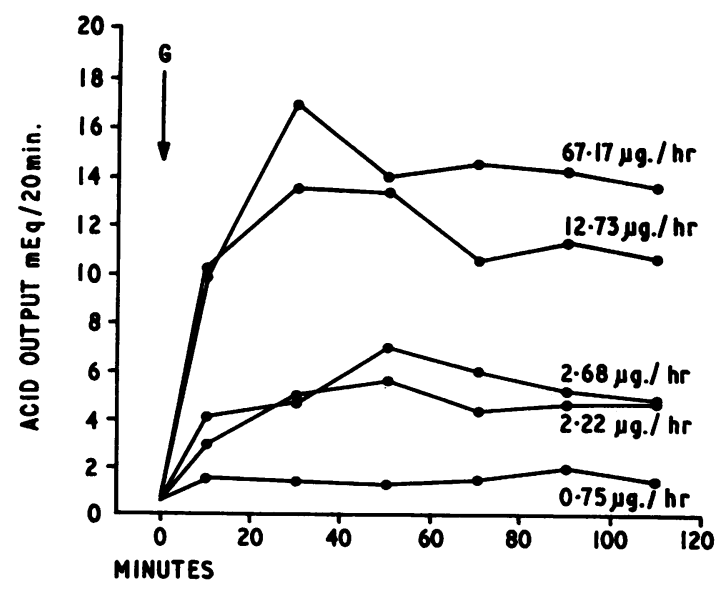

FIG. 1. Plot of acid output in $\mathrm{mEq} . / 20 \mathrm{~min}$. following continuous infusion of graded doses of gastrin II. 
TABLE I

ACID OUTPUT FOR PEAK AND PLATEAU RESPONSES AND SECRETORY RATE FOR PLATEAU RESPONSE AND PEAK ACID OUTPUTS AND CORRESPONDING TOTAL DOSES FOLLOWING CONTINUOUS INFUSION (A) AND SINGLE INTRAVENOUS INJECTIONS (B) OF GASTRIN II

\begin{tabular}{|c|c|c|c|c|c|c|}
\hline Date & Dose ( $\mu g . / h r)$. & Log-dose/hr. & $\begin{array}{l}\text { Peak Output } \\
\text { (mEq./hr.) }\end{array}$ & $\begin{array}{l}\text { Acid Output } \\
\text { Plateau Output } \\
\text { (mEq./2nd hr.) }\end{array}$ & $\begin{array}{l}\text { Mean First } \\
\text { Two Hours }\end{array}$ & $\begin{array}{l}\text { Volume (ml./hr.) for } \\
\text { Second Hour Plateau }\end{array}$ \\
\hline
\end{tabular}

A Continuous intravenous infusion

28. $2.64 \quad 67 \cdot 17$

$19.11 .63 \quad 12 \cdot 73$

$12.11 .63 \quad 4 \cdot 60$

16. $9.63 \quad 2 \cdot 68$

30. $9.63 \quad 2 \cdot 24$

7. 1.64

17.12.63

$0 \cdot 75$

0.21

B Single intravenous injection

13. 3.64

11. 3.64

10. 1.64

6. 1.64

2.12.63

17. 4.64

21.12.63

1.8261
$1 \cdot 1048$
0.6628
0.4292
0.3500
-0.1249
-0.6706

1.6990
1.4770

1.4770

$1 \cdot 2740$

0.6686

0.4931

0.4770

$-0 \cdot 2510$

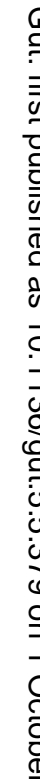

II are shown in Figure 1. Dilution by saliva was minimal, as shown by the high chloride concentration in samples from all tests. The chloride concentration rarely fell below $130 \mathrm{mEq}$./l. Following the start of infusion, secretion increased rapidly with the higher doses. Two phases could be detected in all experiments but were more distinct with the higher doses. In the first phase, a peak of volume and acid output was achieved, usually within 20 minutes, and was maintained within a narrow range for a

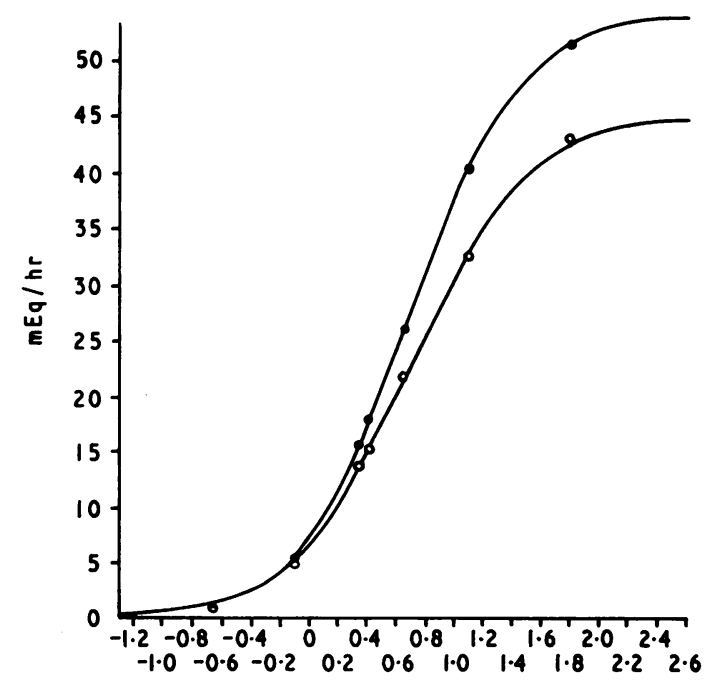

FIG. 2. LOG DOSE

FIG. 2. Dose-response curves of acid output in mEq./hr. against log-dose. The upper curve represents peak output; the lower curve represents second hour steady-state (plateau) output.

FIG. 3. Dose-response curve of secretory rate during the second hour plateau against log-dose. further 40 minutes. This was followed by a lower secretory rate which was then maintained steadily over the second and third hours.

Table I gives acid output values in milliequivalents (volume in $\mathrm{ml}$. $\times$ concentration in $\mathrm{mEq} . / \mathrm{l}$.) obtained from the peak response and from the second hour steady-state (plateau) response. All values in the tables are expressed as per hour. The peak values have been calculated from the peak 40 minutes of the first hour by multiplying this

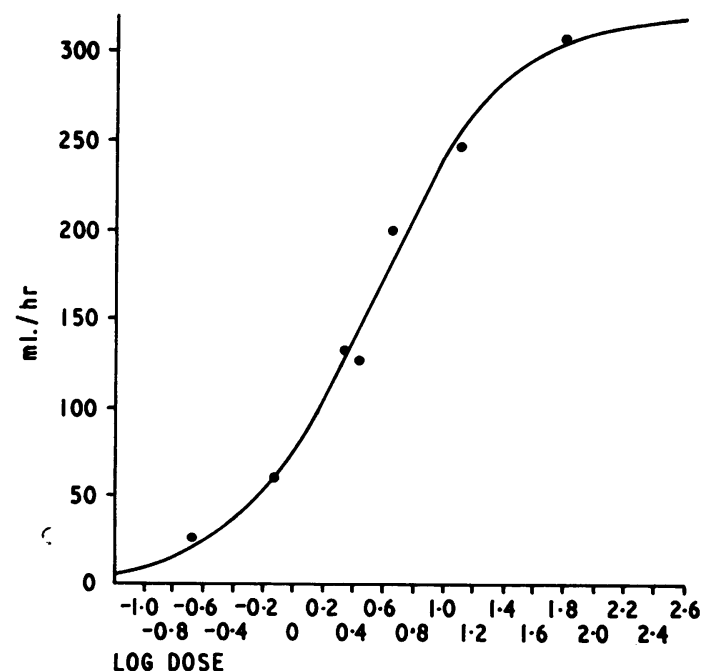

FIG. 3. 
TABLE II

ESTIMATES OF PARAMETERS OF DOSE-RESPONSE CURVES (LOGISTIC)

Equation

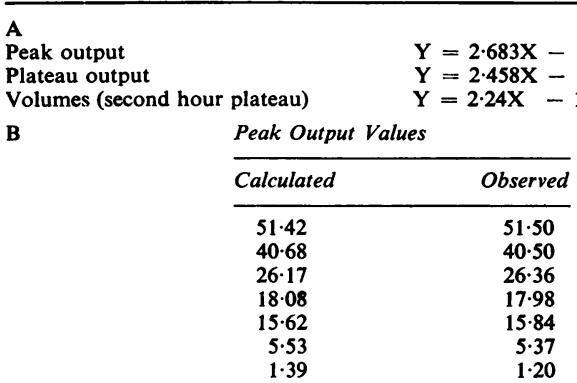

Where $\mathbf{H}=$ maximal output, $\mathbf{Y}=$ logit, and $\mathbf{X}=\log _{10}$-dose

figure by $1 \cdot 5$. Table I also gives the values of the volume output of the second hour steady-state (plateau) response.

Figure 2 shows two plots of acid output per hour against log-dose. The upper curve represents the output of the peak achieved during the first hour and the lower one represents the steady-state values obtained during the second hour. Volumes obtained during the second hour plateau have been treated in a similar manner and are plotted in Figure 3.

It is evident from each set of results that response increases with the dose. The points have been fitted to a logistic function by minimizing the sum of squares of residual deviations of the observed values. The computational method was devised by Woolf (personal communication) and Table II gives the

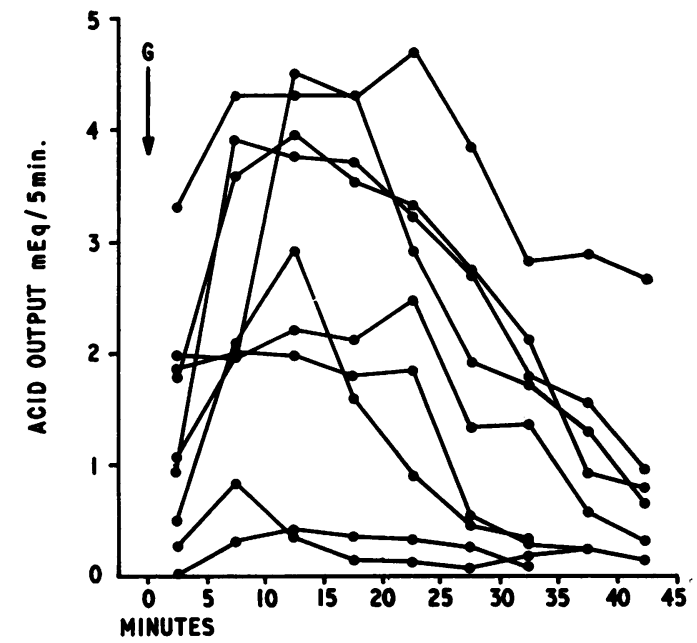

FIG. 4.

FIG. 4. Acid output in mEq./5 min. following administration of single intravenous injections of gastrin II.

FIG. 5. Peak acid output in $\mathrm{mEq} .20 \mathrm{~min}$. against log-dose following administration of single intravenous injection of gastrin II. parameters with their standard errors. From the values of the parameters, a regression equation has been derived of the response in logits on log-dose. Values for a range of logits were then calculated from the equation, and have been expressed as a percentage of $\mathrm{H}$, the maximal value, and plotted on a linear/log scale.

SINGLE INTRAVENOUS INJECTIONS Following single intravenous injections, maximal rates of secretion for a particular dose were achieved rapidly, probably at some time during the first five minutes. Stimulated secretion usually lasted between $\mathbf{3 0}$ and $\mathbf{4 0}$ minutes, except with the highest doses, when it might go on for 80 minutes. In all cases, however, as is illustrated in Fig. 4, a peak of acid output could be clearly distin-

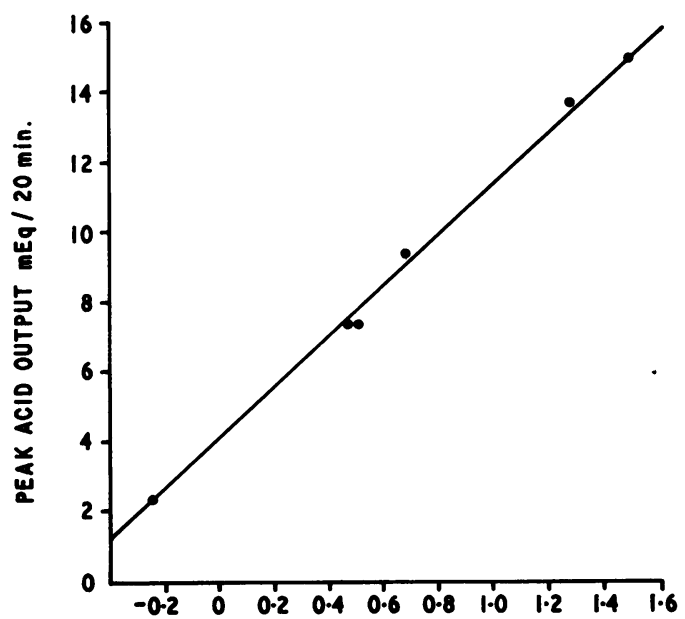

FIG. 5. LOG DOSE GASTRIN 
guished over a 20-minute period between the fifth to 25 th minute or 10th to 30th minute. Over this 20-minute period, secretory rate and acid output per five minutes varied but little. The relationship of this 20-minute peak acid output and the log-dose in the range of doses employed is shown in Figure 5.

\section{SIDE EFFECTS}

Doses between 5 and $50 \mu \mathrm{g}$. injected over a period of five minutes were not attended by symptoms beyond a vague epigastric fullness. On one occasion, when a dose of $20 \mu \mathrm{g}$. was administered rapidly intravenously on a background of continuous maximal infusion, the subject collapsed for a period of 10 minutes without loss of consciousness.

\section{DISCUSSION}

In view of the possible existence of synergism between various stimulants of gastric secretion in dog and man (Gillespie and Grossman, 1964), it is doubtful whether the basal secretion value can be merely subtracted from the value of the stimulated secretion. No attempt at such correction of our data was made. The mean acid output of the basal hour in seven experiments was $1.2 \mathrm{mEq}$. and corresponds to the acid output following the lowest infused dose.

CONTINUOUS INFUSION The practice of taking fiveminute collections allowed a close watch to be kept on the adequacy of the collections and the emergence of a steady-state. The appearance of a first hour peak followed by a steady-state (plateau) in the second hour has already been noted. Adam, Card, Riddell, Roberts, Strong, and Woolf (1954) reported a similar finding following histamine infusion in man, and Gillespie and Grossman (1964) reported the same occurrence following infusion of urecholine in dogs.

The points representing either peak or plateau response plotted against log-dose clearly lie on some kind of sigmoid curve, the particular function chosen depending on the model of gastric secretion which is selected. The logistic function which was chosen represents a model based on simple mass-action theory, in which secretion may be supposed to occur when molecules of a secretory stimulant form addition complexes with a number of secretory units. Table II, giving the standard errors of the estimates and the agreement between calculated and observed values, gives an indication of the goodness of fit obtained. This fit indicates that these results are consistent with the secretory model on which the curve is based, but do not prove it, since the results could also be fitted to other functions based on other hypotheses of acid secretion. The accuracy of the fit, however, indicates how meticulous has been the collection of juice, and how regular is the response of the stomach over a period of several months, in a subject who is completely conditioned to the procedure.

It will be noted that the difference between the peak and plateau responses becomes greater with increasing doses of gastrin II.

The collected volume of juice during the steadystate response (plateau) hour, when plotted against log-dose, also shows a fair fit to the logistic function.

These findings contrast with what is known of the dose-response relationship following the administration of another gastrointestinal hormone, secretin. A linear relationship appears to exist between logdose and pancreatic flow following continuous infusion of secretin in anaesthetized dogs (Grossman, 1958, after Greengard, Stein, and Ivy, 1941), and in man (Lagerlöf, 1942). The relationship, however, between pancreatic flow and the arithmetic value of the dose is sigmoid. It is not possible at present to explain the apparently contrasting behaviour of these two gastrointestinal hormones.

SINGLE INTRAVENOUS INJECTIONS The secretory response following intravenous injection of gastrin II occurs rapidly. A short latency appears to be a property shared by gastrointestinal hormones (Grossman, 1958). Recent experiments on rats (Amure and Ginsburg, 1964) demonstrate a short latency following intravenous administration of crude gastrin extract, and a virtually undetectable latency following administration into the gastric intra-arterial circulation. Our own experience in man confirms these findings. Following intravenous injection of $3 \mu \mathrm{g}$. of gastrin II over a period of 30 seconds, secretory flow was evident within two minutes. The volumes collected during each of the first three five-minute periods were equal and were followed by a slow decline. If account is taken of the circulation time from forearm to stomach, the latency of this dose of gastrin would appear to have been less than one minute.

The problem of establishing an accurate doseresponse relationship following single intravenous injections is more complex than for continuous infusion. Teorell (1937) formulated the kinetics of distribution of a drug in the tissues following various modes of administration, and demonstrated that a 'prompt' single intravenous injection can be considered as a limiting case of subcutaneous injection in which the resorption rate from a tissue depot is rapid. He derived two important conclusions. First, that the time of appearance of 'maximal' concentration of the drug in the tissues for a particular dose and, by inference, of 'maximal' response 
from the stimulated organ, is independent of the dose injected. Secondly, that the height of this maximal tissue concentration of the drug is proportional to the amount of drug injected.

That the first conclusion is valid for this series of experiments can be seen from the plot of Fig. 4, where the peaks are achieved over nearly the same period independently of the dose administered. But if the dose is given more slowly over five minutes, as was the case with the higher doses of gastrin II, the time of appearance of the peak will be slightly shifted to the right, e.g., between the tenth and 30th minutes instead of between the fifth and 25th minutes. The acid outputs derived from the fiveminute collections over the 20 -minute period of the peak are equal within narrow limits.

The magnitude of the peak output is a function of the maximal concentration of the drug in the tissues following the administration of a particular dose of gastrin II, and when the peak output is plotted against the logarithm of the total dose it shows a nearly linear relation over a range of doses. This possibly represents the linear section of a sigmoid dose-response curve. The validity of plotting the total administered dose against the peak output derives from the fact mentioned earlier that maximal tissue concentration of a drug is directly proportional to the total administered dose.

A similar relationship between peak output and the log-dose of histamine following subcutaneous administration has also been demonstrated in dogs by Öbrink (1948) and. more recently, by Marks, Komarov, and Shay (1960). A relationship between the log-dose of histamine and the total output, however, can only be demonstrated over the middle range of doses (Öbrink, 1948).

THE MAXIMAL RESPONSE TO GASTRIN Gastrin II was administered to the same subject by a variety of routes and in doses that produced in each case a maximal response. The values of these maximal acid outputs are shown in Table III and can be seen to be similar and independent of the mode of administration. Thus the peak acid output over a 20 -minute

\section{TABLE III}

MAXIMAL ACID OUTPUT AFTER VARIOUS MODES OF ADMINISTRATION OF GASTRIN II

\begin{tabular}{llc} 
Mode of Administration & Dose & Peak Output $(\mathrm{mEq} . / \mathrm{hr})$. \\
\hline Continuous infusion & $67 \mu \mathrm{g} . / \mathrm{hr}$. & $51 \cdot 5$ \\
Single intravenous injection & $50 \mu \mathrm{g}$. & $51 \cdot 1$ \\
Subcutaneous injection & $2 \mu \mathrm{g} / \mathrm{kg}$. & $50 \cdot 4$ \\
Intermuscular injection & $1 \mathrm{\mu g} / \mathrm{kg}$. & $49 \cdot 0$
\end{tabular}

period following intravenous administration of gastrin II is $17 \cdot 37 \mathrm{mEq}$., i.e., $52 \cdot 11 \mathrm{mEq}$./hr. (Table I). The peak acid output following continuous infusion is $51.5 \mathrm{mEq}$./hr. (Table I). The peak acid outputs following administration of gastrin II subcutaneously $(2 \mu \mathrm{g} . / \mathrm{kg}$.) and intramuscularly $(1 \mu \mathrm{g} . / \mathrm{kg}$.) are $50.4 \mathrm{mEq}$. and $49 \mathrm{mEq}$. respectively (Makhlouf, McManus, and Card, 1964, in the press). Marks et al. (1960) demonstrated a high correlation between the parietal cell mass and the peak acid secretory output either following a single large subcutaneous injection or continuous infusion of histamine in dogs. Card and Marks (1960) established a similar relationship between the parietal cell mass and the post-histamine hour in man. More recently, Makhlouf et al. (1964) demonstrated a linear relationship $(r=0.992)$ between maximal gastrin and histamine acid outputs in 16 human subjects. Moreover, the acid output during the post-stimulatory hour bears a direct and highly significant $(r=0.995)$ linear relationship to the peak acid output. It would appear then that the maximal output from a given stomach is the same following different modes of administration of gastrin II and is consistent with the hypothesis correlating parietal cell mass and the maximal acid output following a secretory stimulant.

\section{SUMMARY AND CONCLUSIONS}

The effects of increasing doses of gastrin II given by continuous infusion and single intravenous injections in a healthy male volunteer are described. The peak acid outputs as well as the plateau acid outputs and secretory rates following continuous infusion plotted against the corresponding log-dose were fitted to a logistic function. A relationship between the peak acid output and log-dose following single intravenous injections is also demonstrated. The latency following intravenous administration of gastrin II appears to be very short. The significance of the peak acid output following various modes of administration of gastrin II and its relationship to the parietal cell mass is discussed.

We should like to express our gratitude to Professor R. A. Gregory for his valuable advice and for his generous gift of gastrin II. We should also like to thank Professor R. B. Fisher and Dr. Christine Thomson for their helpful criticism, and Dr. B. Woolf for advice on statistical methods. The technical procedures were carried out in the Teaching and Research Centre of the Western General Hospital, Edinburgh. This work was supported by a grant from the Medical Research Council.

\section{REFERENCES}

Adam, A. M., Card, W. I., Riddell, M. J., Roberts, M., Strong, J., and Woolf, B. (1954). Dose-response curves for the effect of histamine on acid gastric secretion in man. Brit. J. Pharmacol., 9, 329-334.

Amure, B. O., and Ginsburg, M. (1964). Effects of gastrin in the rat. J. Physiol. (Lond.), 170, 30-31 p. 
Card, W. I., and Marks, I. N. (1960). The relationship between the acid output of the stomach following 'maximal' histamine stimulation and the parietal cell mass. Clin. Sci., 19, 147-163.

Gillespie, I. E. and Grossman, M. I. (1964). Potentiation between Urecholine and gastrin extract and between Urecholine and histamine in the stimulations of Heidenhain pouches. Gut, 5, 71-76.

Greengard, H., Stein, I. F., Jr., and Ivy, A. C. (1941). Certain quantitative aspects of the pancreatic response to secretin. Amer. J. Physiol., 132, 305-309.

Gregory, R. A., and Tracy, Hilda, J. (1964). The constitution and properties of two gastrins extracted from hog antral mucosa. Gut, 5, 103-117.
Grossman, M. I. (1958). The physiology of secretin. Vitam. Horm., 16, 179-203.

Lagerlöf, H. O. (1942). Pancreatic function and pancreatic disease studied by means of secretin. Acta med. scand., suppl. 128, 1 .

Makhlouf, G., McManus, J., and Card, W. I. (1964). The action of gastrin II on gastric acid secretion in man. In the press.

Marks, I. N., Komarov, S. A., and Shay, H. (1960). Maximal acid secretory response to histamine and its relation to parietal cell mass in the dog. Amer. J. Physiol., 199, 579-588.

Obrink, K. J. (1948). Studies on the kinetics of the parietal secretion of the stomach. Acta physiol. scand., 15, suppl. 51.

Teorell, T. (1937). Kinetics of distribution of substances administered to the body. Arch. int Pharmacodyn., 57, 205-225. 